\title{
Dualidade estrutural no ensino técnico profissionalizante em Brasília (IFB): uma análise do discurso oficial de inclusão e as dificuldades de permanência dos alunos*
}

\section{Structural duality in professional technical education in Brasilia (IFB): an analysis of the official discourse of inclusion and the difficulties of students staying}

\author{
Claudio Nei Nascimento da Silva ${ }^{1}$ \\ Fernanda Conciani ${ }^{2}$ \\ Márcio Adriano de Azevedo 3 \\ Cristiane Jorge Lima Bonfim ${ }^{4}$ \\ Oswaldo Junqueira Vaz Júnior ${ }^{5}$ \\ Evelynne Katriny Silva de Sousa Miranda ${ }^{6}$ \\ Maiane Araújo Souza
}

\begin{abstract}
Resumo: Esta pesquisa teve o objetivo de analisar as causas e as consequências da evasão no Instituto Federal de Brasília, à luz do fenômeno sociológico da dualidade estrutural em comparação com o discurso oficial da inclusão presente nos documentos institucionais. Os resultados revelaram que apesar do discurso oficial da inclusão, a dualidade estrutural continua presente como fator explicativo do fracasso escolar dos estudantes por meio da evasão, que se revelou em altas taxas nos cursos técnicos com duração de um ano e meio, e de uma permanência deficiente, quando não conseguem conciliar trabalho e estudo.
\end{abstract}

\section{Palavras-chave: Educação Profissional; Dualidade Estrutural; Inclusão.}

Abstract: This research aimed to analyze the causes and consequences of evasion the Federal Institute of Brasilia, in the light of the sociological phenomenon of the 'structural duality in comparison with the official discourse of inclusion in this institutional documents. The results revealed that despite the official discourse of inclusion, structural duality is still present as an explanatory factor for the school failure of students through the evasion, revealed in high rates in technical courses with one and a half year length, and an inefficient permanency when they are not able to combine work and study.

\footnotetext{
* Esta pesquisa foi financiada pelo Edital no 35/2011CDIT/PRPI/PREX/PREN de 06 de maio de 2011. Programa de incentivo à pesquisa integrada do IFB.

${ }^{1}$ Pedagogo, Mestre em Educação pela UCB e Doutorando em Ciência da Informação pela Universidade de Brasília - UnB. Docente do Instituto Federal de Brasília, da área de Educação.

2 Docente do IFB entre 2011 e 2012 e atualmente mestranda em Letras Modernas pela Universidade de Versailles St-Quentin-en-Yvelines/França.

${ }^{3}$ Pedagogo, Mestre e Doutor em educação pela UFRN. É professor e coordenador da educação superior no Campus Natal Central do Instituto Federal do Rio Grande do Norte.

${ }^{4}$ Bacharel em Sistemas de Informação pelo Centro Universitário Luterano de Palmas. Mestre em Educação pela UnB. Docente do IFB no Eixo de Informação e Comunicação.

${ }^{5}$ Graduado em Administração pelo Centro Universitário do Distrito Federal. Docente da área de administração e Lógistica no IFB.

${ }^{6}$ Bolsista, aluna do Instituto Federal de Brasília, Campus Gama.

${ }^{7}$ Bolsista, aluna do Instituto Federal de Brasília, Campus Gama.
} 


\section{Keywords: professional technical education; structural duality; inclusion INTRODUÇÃO}

O discurso da inclusão social através da educação deve ser compreendido como síntese de um processo histórico de conquistas relacionado à consolidação do Estado Democrático de Direito, conforme defende Jamil Cury (2008). O pressuposto antagônico da inclusão é a desigualdade social, uma chaga histórica na realidade brasileira, uma disfunção social que se manifesta na escola, limitando seu potencial transformador, seja no campo coletivo, seja no campo individual. A base da desigualdade social está no surgimento da sociedade de classes, quando houve um aprofundamento da divisão social do trabalho, na passagem do comunismo primitivista para o escravismo, o que possibilitou também uma divisão nos fins da educação, isto é, uma dualidade na sua destinação. Para Saviani (2007, p. 155 - 156) "com a divisão dos homens em classes a educação também resulta dividida; diferencia-se, em consequência, a educação destinada à classe dominante daquela a que tem acesso a classe dominada". Mas o conceito de dualidade estrutural está fundado na teoria da escola dualista de Baudelot e Establet (1971 apud SAVIANI, 2007a) que desconstrói a ideia de que a escola não é unitária e nem unificadora, mas se divide em duas, sendo uma voltada para a educação dos filhos dos trabalhadores e a outra voltada para a burguesia. Essa dualidade estrutural tem estado presente em toda a história da educação brasileira. Mesmo em períodos mais recentes, onde uma desejada maturação institucional revelaria uma sociedade mais justa, essa dualidade continua presente. A literatura educacional tem indicado claramente que, apesar de inúmeras medidas supostamente inclusivas tomadas no campo da educação, a dualidade estrutural continua sendo uma categoria explicativa importante da sociedade brasileira, que teve no ensino médio profissionalizante sua marca mais evidente.

Até 1961 não havia equivalência entre o ensino médio profissionalizante e o ensino propedêutico, o que caracterizava efetivamente o projeto dualista da sociedade através da educação. Esse problema foi corrigido pela Lei 4.024/1961. Mesmo assim, essa bifurcação na trajetória escolar dos estudantes não se encontra superada, pois "embora constitua um importante avanço, a equivalência não supera a dualidade estrutural" (SILVA, 2004, p. 28), que permaneceu tendo no currículo das escolas sua causa, porque inviabilizou que os filhos das classes trabalhadoras recebessem os conteúdos necessários para ingresso no ensino universitário.

A Lei 5.692/1971, ao promover uma reforma no ensino básico, no bojo da retomada da industrialização no contexto do chamado "milagre econômico" torna a profissionalização compulsória para todos os estudantes. Desse modo, "utilizou- se, então, a via da profissionalização no $2^{\circ} \mathrm{grau}$, o que, supostamente, garantiria a inserção no mercado de trabalho" (MOURA, 2010, p. 878). Embora o objetivo tenha sido enfrentar o problema da dualidade, essa profissionalização comprometeu a formação geral básica que ficou enfraquecida nos sistemas estaduais, que ofereceram, quando muito, uma formação aligeirada para as demandas mais instrumentais dos processos de produção industrial, conforme argumenta Moura (2010). 
A atual Lei de Diretrizes e Bases da Educação Nacional, Lei 9.394/1996, tornou o ensino médio profissionalizante subsequente à Educação Básica, o que na prática resultou em mudanças apenas para os interessados em ingressar na educação profissional, isto é, os filhos dos trabalhadores, que só puderam acessar a educação profissional depois de concluído o ensino médio básico. Além do mais, isso pode ter representado uma dificuldade a mais para os filhos das classes desfavorecidas para os quais se exigia mais tempo de escolarização antes de adquirir condições mínimas para as exigências do mercado de trabalho, um diploma de curso técnico.

O Decreto 2.208/1997 retoma a possibilidade de articulação entre o ensino profissionalizante e o ensino médio quando cria formas concomitante e subsequente. Para essa última, esse Decreto não supera a dualidade mas, ao contrário, representa uma forma de destinação quase exclusiva para aqueles que, embora tivessem cursado o ensino médio, não conseguiam obter as condições necessárias para ingresso no ensino superior, de maneira que os tornam, portanto, clientes potenciais dos cursos técnicos subsequentes.

Em 2004, a proposta de integração do ensino médio com o ensino profissionalizante é retomada com o Decreto 5.154/2004, que propõe a forma integrada, o que, segundo Moura (2010, p. 883),

representa uma possibilidade de avanço na direção de construir um ensino médio igualitário para todos, pois, apesar de não se confundir com a politecnia, fundamenta-se em seus princípios e é exigência de uma sociedade na qual a elevada desigualdade socioeconômica obriga grande parte dos filhos das classes populares a buscar, bem antes dos 18 anos de idade, a inserção no mundo do trabalho, visando a complementar a renda familiar.

Em 2008, a Lei 11.741 devolve a dupla equivalência ao ensino médio profissionalizante quando cria a forma integrada e concomitante, de maneira a oportunizar aos interessados possibilidade de receber, de forma concomitante à conclusão da educação básica, um diploma de curso profissionalizante.

Com a criação dos Institutos Federais pela Lei $11.892 / 2008$, o ensino profissionalizante ganhou novo fôlego no Brasil, através da expansão da rede federal de ensino e de uma nova concepção de ensino profissional, tendo na categoria trabalho o fundamento do processo educativo.

Nesses casos, as mudanças foram orientadas a partir de concepções que tomavam a educação como responsável senão importante instrumento de emancipação dos cidadãos que se pretendiam partícipes da vida política e social, o que na realidade não resultou na superação da dualidade própria de uma sociedade fortemente marcada pela desigualdade social.

Com a finalidade de avaliar a efetividade destes instrumentos para a melhoria das condições de competitividade profissional dos estudantes, a pesquisa 
apresentada neste trabalho evidenciou as dificuldades encontradas pelos estudantes para se manterem frequentes nos cursos, como também para terem uma formação verdadeiramente de qualidade.

\section{PROCEDIMENTOS METODOLÓGICOS}

Esta pesquisa enquadrou-se no modelo de estudo descritivo e se insere na abordagem qualitativa, tomando o levantamento e tratamento de dados quantitativos numa perspectiva complementar. A abordagem qualitativa se adéqua melhor a explicar a realidade e o ambiente dessa pesquisa, entretanto, alguns dados, face à natureza dos objetivos específicos, tiveram que ser coletados através de questionários, gerando, com isso, dados quantitativos que contribuíram para complementar 0 entendimento dos resultados. 0 caso analisado nesta pesquisa refere-se aos cursos técnicos em Logística, Cooperativismo e Agronegócio oferecidos no Campus Gama.

\section{Instrumentos}

Foram utilizados como instrumentos desta pesquisa a entrevista semiestruturada, o questionário de múltipla escolha e a análise documental. Cada instrumento levou em consideração suas especificidades e a eficácia de sua utilização em cada grupo pesquisado, isto é, professores e alunos. Portanto, além da necessidade de alcance dos objetivos específicos da pesquisa, também procurou considerar as particularidades de cada grupo e o instrumento mais adequado ao grupo selecionado. Com os professores foram realizadas entrevistas semiestruturadas e com os alunos foram aplicados questionários de múltipla escolha.

\section{Entrevistas}

A definição da entrevista como um dos instrumentos de coleta de dados levou em consideração alguns aspectos, como: o universo de pesquisados (no caso, os professores), a natureza de sua função no caso estudado, maior confiabilidade na coleta dos dados em relação ao grupo específico de entrevistados. Para Bogdan e Biklen (2010, p. 134) "em todas as situações, a entrevista é utilizada para recolher dados descritivos na linguagem do próprio sujeito, permitindo ao investigador desenvolver intuitivamente uma ideia sobre como os sujeitos interpretam o mundo".

O processo de utilização da entrevista na pesquisa iniciou-se com o estudo sobre os limites e as possibilidades desse instrumento na pesquisa qualitativa. $O$ estudo envolveu os professores pesquisadores e os alunos bolsistas e teve como referência os seguintes aspectos dessa técnica: critérios de seleção dos sujeitos; protocolo de entrevista; desenvolvimento da entrevista; limitações da entrevista; e análise e processamento dos dados das entrevistas, conforme Couto (2008).

A composição do grupo de nove professores entrevistados obedeceu ao critério da "heterogeneidade da amostra, em variáveis consideradas analiticamente relevantes" (COUTO, 2008, p. 52). Desse modo, a etapa levou em consideração: - curso que o entrevistado estava vinculado (Cooperativismo, Logística e 
Agronegócio); tipo de formação (bacharelado e licenciatura); tempo na instituição (veteranos e novatos); e experiência na docência (quem possuía e quem não possuía). A cobertura desses aspectos sobre o grupo de entrevistados foi considerada relevante porque são consideradas variáveis capazes de influenciar no conteúdo das entrevistas.

A análise das entrevistas seguiu um processo de categorização dos dados em que foi possível comparar as convergências e as divergências entre as falas dos entrevistados.

\section{Análise documental}

A análise documental buscou verificar as perspectivas político-ideológicas subjacentes aos documentos oficiais. Para tanto, esteve fundamentada nas contribuições de Bardin (1977) sobre as formas de organização da análise de conteúdo. Segundo esse autor, a análise de conteúdo deverá obedecer a três etapas: i) pré-análise; ii) exploração do material; (iii) e tratamento dos resultados, inferência e interpretação. Para considerar as três etapas previstas na teoria, foi elaborado um instrumento que buscou caracterizar o documento a ser analisado, as partes do documento isoladas para análise e a devida interpretação e inferência. Além disso, estabeleceu-se um processo de codificação, mediante o qual foi possível atingir a representação do conteúdo e a expressão da ideia que nele estava contida.

\section{Questionário}

Foram aplicados questionários a todos os alunos dos cursos técnicos em Agronegócio, Cooperativismo e Logística, perfazendo um total de 126 alunos. Os questionários de múltipla escolha continham 21 questões que abordavam: 0 perfil dos alunos em relação à idade, estado civil, renda familiar, número de filhos, escolaridade dos pais; as condições e perspectivas profissionais dos estudantes; e uma avaliação sobre a qualidade do curso. Depois de aplicados, os dados dos questionários foram processados e convertidos em tabelas, como o objetivo de complementar a análise das informações oriundas das entrevistas.

\section{A REALIDADE SOCIOECONÔMICA DOS ALUNOS E O ENSINO TÉCNICO}

Quando da análise do perfil dos alunos dos cursos técnicos, verificou-se que a maioria encontra-se numa idade acima daquela imediatamente subsequente a faixa etária do ensino médio básico, que é de 15 a 17 anos de idade.

Em relação à faixa etária, a frequência maior ficou entre 26 a 33 anos. A pesquisa levantou que $18 \%$ dos alunos dos cursos técnicos em Logística, Cooperativismo e Agronegócio apresentam idade superior a 42 anos e a maioria se encontra inserida no mercado de trabalho, ou seja, são trabalhadoresestudantes e não estudantes-trabalhadores. Isso quer dizer que sua condição primeira é de trabalhador, o que aponta sinais claros de quais são realmente suas prioridades na vida, como também para o fato de que concluíram o ensino 
médio há muitos anos, podendo ser este um fator complementar a dificultar o acompanhamento nas aulas.

Nesse sentido, o trabalho, seja por sua condição estruturante, seja por sua condição consequente, tem servido para explicar as dificuldades encontradas pelos alunos nos cursos técnicos profissionalizantes. Independente das condições do trabalho que desempenham, formal ou informal, a condição de trabalhador sobrepõe à condição de estudante nos cursos técnicos analisados, conforme demonstra o Tabela 01.

Tabela 1 - Situação ocupacional dos alunos

\begin{tabular}{lr}
\multicolumn{1}{c}{ Situação apresentada } & \% \\
\hline Trabalha, está empregado com carteira de trabalho assinada. & 36 \\
\hline Trabalha, mas não tenho carteira de trabalho assinada. & 8 \\
\hline Trabalha por conta própria, não tem carteira de trabalho assinada. & 7 \\
\hline Já trabalhou, mas não está trabalhando. & 41 \\
\hline Nunca trabalhou. & 5 \\
\hline Nunca trabalhou, mas está procurando trabalho. & 3 \\
\hline
\end{tabular}

Fonte: Pesquisa de Campo 2011

Além disso, outra condição inerente à condição desses estudantes é a paternidade/maternidade, que está presente em quase a metade dos estudantes (49\%). Ainda assim, este não foi um aspecto principal apontado pelos professores em relação às dificuldades que os alunos apresentam na sala de aula. Do ponto de vista do estado civil, mais da metade (56\%) afirmou ser solteira, sendo o restante, casados ou separados.

A renda familiar dos estudantes que afirmaram estar inseridos no mercado de trabalho foi outro aspecto relevante do perfil socioeconômico, pois $62 \%$ desse grupo recebem até dois salários mínimos, definindo contornos sociais e econômicos claros da clientela atendida nos cursos técnicos. Conquanto, para $12 \%$ desse mesmo grupo, a renda salarial supera cinco salários mínimos, podendo chegar à faixa dos 10 a 30 salários mínimos. Em que possa essa diversidade refletir na heterogeneidade do grupo, é preciso lembrar que se refere aos alunos que afirmaram ter ocupação laboral, isto é, aos $51 \%$ dos que possuem alguma ocupação.

A baixa escolaridade dos pais dos alunos participantes da pesquisa é de importante destaque, haja vista que não mais que $2 \%$ têm curso superior. Em vista disso, pode-se supor que a base de formação social e profissional do cidadão se consolida na formação superior, de forma que, o marco referencial da criança e do adolescente é a exemplificação paterna e materna, consolidados em ambiente familiar. Esse referencial encontra-se pendente nos alunos pesquisados, o que pode resultar em desarranjos estruturais e culturais na formação daqueles que são oriundos desse ambiente. Essa é uma condição importante para se compreender a evasão, porque não se encontra contemplada na constatação de que o percentual de pessoas com nível superior cresce a cada 
geração, por circunstâncias próprias do desenvolvimento social humano por que passam as sociedades modernas.

Em suma, os estudantes que procuraram o curso técnico subsequente em Brasília, no Campus Gama, são, em geral, oriundos de classes menos favorecidas, estão desempregados e a procura de emprego ou estão empregados com baixa remuneração, são filhos de pais pouco escolarizados (cerca da metade apresenta apenas o ensino fundamental completo), metade tem filhos e estão numa faixa etária bem acima da maioria dos egressos do ensino médio.

\section{DUALIDADE ESTRUTURAL}

A dualidade estrutural é uma categoria que explica a escola a partir de suas finalidades. A esse respeito, Kuenzer afirma que ela "expressou- se por meio da oferta de escolas que se diferenciavam segundo a classe social que se propunham a formar: trabalhadores ou burgueses" (2007, p. 1155). Trata-se, portanto, de uma forma de conceber a escola e a educação, isto é, de um lado, tomar a educação como algo capaz de contribuir para que os filhos das famílias mais aquinhoadas possam receber o ensino universitário e com isso ocupar e/ou permanecer em posições privilegiadas na sociedade; e de outro lado, uma educação que apenas reproduz as dificuldades sociais a partir da destinação dos filhos das famílias trabalhadoras para uma formação técnica, manual e com remuneração e prestígio reduzidos. Nesse sentido, a pesquisa mostrou que a dualidade estrutural transcende a dimensão da destinação pedagógica quando consegue se manifestar de modo concreto no ambiente da sala de aula, conforme relato dos professores entrevistados.

Os problemas de ordem socioeconômica principalmente, em virtude de alguns alunos chegarem ao Instituto [Federal de Brasília] com alguma carência de formação, seja por dificuldades econômicas, seja por não terem tido acesso a uma formação mais consistente, é uma deficiência que tem como causa um problema socioeconômico. A falta de dinheiro dificultou esse aluno a ter acesso a um ensino mais consistente e isso aí acaba acarretando nas nossas aulas (Professor 01).

Principalmente as questões socioeconômicas, alguns alunos necessitam de emprego, necessitam de renda e o que eles alegam são duas coisas: primeiro que não chegam a tempo; segundo, muitos acabam desistindo porque só chegam para a segunda ou terceira aula. (Professor 03).

Sim (os problemas de ordem socioeconômicas) interferem, não para associar a realidade que essas pessoas trazem para a sala de aula que todas as deficiências sociais econômicas refletem tanto no ensino quanto como na aprendizagem e até mesmo na convivência entre eles em sala de aula. Então é um 
tema presente na sala de aula, direta ou indiretamente. (Professor 06).

Essa correspondência entre origem social do educando e sua manifestação na prática discente da sala de aula reforça a tese de que a dualidade é um problema que encontra diferentes formas de se afirmar socialmente e embora políticas públicas de enfrentamento estejam sendo implementadas, a escola ainda se divide em duas, conforme a origem social de seus alunos. Além disso, outros aspectos se evidenciaram na pesquisa e podem contribuir para reforçar as dificuldades dos alunos em tomar a educação como mecanismo de superação de suas próprias dificuldades, conforme análise a seguir.

\section{DETERMINANTES SOCIAIS PARA A PERMANÊNCIA NOS CURSOS}

Além das dificuldades mencionadas, os professores relataram que em sala de aula essas dificuldades se manifestam mais claramente na sua relação com os alunos. Em geral, as dificuldades estão ligadas à relação entre trabalho e estudo, impondo limites de tempo e condições para que o aluno realize atividade extraclasse e possa estudar em casa o conteúdo das aulas. Outras dificuldades foram apontadas pelos professores como sendo fatores que comprometem 0 desempenho dos estudantes nos cursos, trazendo consequências para a permanência do aluno. As dificuldades encontradas se dividem entre aquelas que pertencem e se circunscrevem à subjetividade discente (endógenas) e aquelas ligadas ao seu contexto (exógenas), conforme quadro 01 a seguir:

\section{Quadro 01 - Dificuldades dos alunos em relação ao curso}

\begin{tabular}{l|l}
\multicolumn{1}{c|}{ Endógenas } & \multicolumn{1}{c}{ Exógenas } \\
$\begin{array}{l}\text { Acompanhamento do conteúdo das } \\
\text { aulas }\end{array}$ & $\begin{array}{l}\text { Ausência de estrutura de apoio ao } \\
\text { aluno (física, pedagógica e social) }\end{array}$ \\
\hline Atraso nas aulas & $\begin{array}{l}\text { Distância e dificuldades de acesso } \\
\text { aos locais do curso }\end{array}$ \\
\hline $\begin{array}{l}\text { Desconhecimento prévio do curso, } \\
\text { em relação ao perfil do egresso. }\end{array}$ & $\begin{array}{l}\text { Falta de flexibilidade no ambiente de } \\
\text { trabalho para realizar atividades do } \\
\text { curso }\end{array}$ \\
\hline Desmotivação em relação ao curso & $\begin{array}{l}\text { Necessidade de trabalhar para } \\
\text { ajudar no orçamento doméstico }\end{array}$ \\
\hline Falta de pré-requisito & $\begin{array}{l}\text { Falta de planejamento da instituição } \\
\text { em relação à operacionalidade do } \\
\text { curso }\end{array}$ \\
\hline $\begin{array}{l}\text { Falta de tempo para as atividades } \\
\text { do curso }\end{array}$ & \multicolumn{1}{|c}{} \\
\hline
\end{tabular}

A dimensão social aparece de forma clara na composição das dificuldades enfrentadas pelos alunos, em especial pela falta de tempo ou condições para conciliar trabalho e estudo. A dificuldade dessa conciliação confronta com a possibilidade de tomar o trabalho e educação como instâncias associadas, que se autocolaboram para a formação do cidadão. Esse problema se agrava ainda mais quando se constata o perfil dos estudantes, em sua maioria trabalhadores. A 
relação entre trabalho e escola, que deve ser uma relação de colaboração, tornase um fator dificuldade e, segundo Saviani (2007, p. 157), "reflete, por sua vez, a divisão que se foi processando ao longo a história entre trabalho manual e trabalho intelectual". Com isso, a face implícita da dualidade estrutural se manifesta no Instituto Federal de Brasília - IFB através de cursos e programas implantados sob o discurso da inclusão, que continuam tendo a reprodução social como principal consequência. A evasão se torna, portanto, a maior consequência dos problemas enfrentados pelos alunos, conforme Quadro 02.

\section{Quadro 02 - Dificuldades de permanência dos alunos e suas consequências}

\begin{tabular}{|c|c|c|c|c|c|c|c|c|}
\hline $\begin{array}{c}\text { Causas/ } \\
\text { consequências }\end{array}$ & $\begin{array}{l}n \\
0 \\
0 \\
0 \\
\frac{1}{2} \\
\frac{1}{4}\end{array}$ & 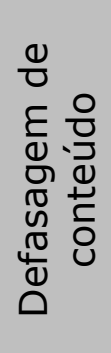 & 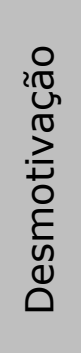 & 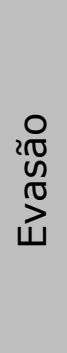 & $\begin{array}{l}\frac{n}{\mathbb{N}} \\
\frac{ \pm}{\mathbb{N}} \\
\longleftarrow\end{array}$ & 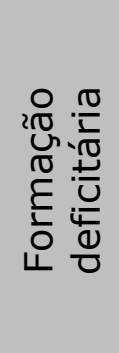 & $\begin{array}{l}0 \\
\frac{0}{0} \\
\frac{\pi}{0} \\
\frac{0}{0} \\
\frac{1}{0} \\
\frac{0}{0} \\
\frac{0}{0} \\
\frac{1}{0} \\
\frac{1}{1}\end{array}$ & 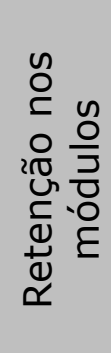 \\
\hline $\begin{array}{l}\text { Dificuldade no } \\
\text { acompanhamento do } \\
\text { conteúdo das aulas. } \\
\end{array}$ & & & $x$ & $x$ & & & $x$ & \\
\hline Atraso nas aulas & & & & $x$ & & & & \\
\hline $\begin{array}{l}\text { Ausência de estrutura } \\
\text { de apoio ao aluno } \\
\text { (física, pedagógica e } \\
\text { social) }\end{array}$ & & & & $x$ & & $x$ & & $x$ \\
\hline $\begin{array}{l}\text { Desconhecimento } \\
\text { prévio do curso }\end{array}$ & & & & $x$ & & $x$ & & $x$ \\
\hline $\begin{array}{l}\text { Desmotivação em } \\
\text { relação ao curso }\end{array}$ & & & & $x$ & & & & \\
\hline $\begin{array}{l}\text { Dificuldade no } \\
\text { entendimento dos } \\
\text { conteúdos/falta de } \\
\text { pré-requisito. }\end{array}$ & & & & $x$ & & $x$ & & $x$ \\
\hline $\begin{array}{l}\text { Distância e dificuldades } \\
\text { de acesso aos locais do } \\
\text { curso }\end{array}$ & $x$ & & & $x$ & $x$ & & & \\
\hline $\begin{array}{l}\text { Falta de flexibilidade } \\
\text { no ambiente de } \\
\text { trabalho para realizar } \\
\text { atividades do curso. }\end{array}$ & $x$ & & & $x$ & $x$ & & & \\
\hline $\begin{array}{l}\text { Falta de planejamento } \\
\text { da instituição em } \\
\text { relação à } \\
\text { operacionalidade do } \\
\text { curso. }\end{array}$ & & & $x$ & $x$ & & & & \\
\hline $\begin{array}{l}\text { Falta de tempo para as } \\
\text { atividades do curso }\end{array}$ & & $x$ & & & & $x$ & & \\
\hline
\end{tabular}


Necessidade de trabalhar para ajudar no orçamento doméstico

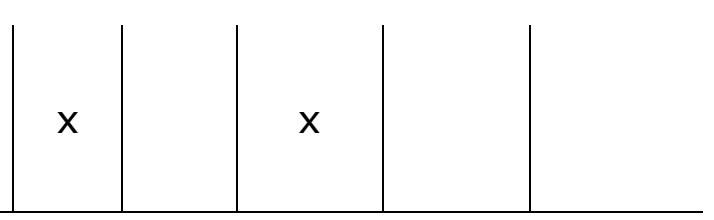

A evasão se mostrou como a consequência da maioria dos problemas enfrentados pelos alunos, seguida da formação deficitária. Os números oficiais da evasão mostram uma evolução em todos os cursos analisados, conforme verificado na Tabela 02. A realidade mais grave foi verificada no curso Técnico em Cooperativismo que, embora no segundo semestre do ano de 2011 ainda não tivesse chegado no terceiro módulo, a taxa de evasão já atingia 75,5\%.

Tabela 02 - Evolução da taxa de evasão* nos cursos Técnicos IFB/Gama 2011.2**

\begin{tabular}{lccc}
\hline & 10 Módulo & 20 Módulo & 30 Módulo \\
\hline Tec. em Agronegócio & $27,5 \%$ & $62,5 \%$ & - \\
\hline Tec. em Cooperativismo & $0,0 \%$ & $75,5 \%$ & - \\
\hline Téc. em Logística & $2,5 \%$ & $37,5 \%$ & $47,5 \%$ \\
\hline
\end{tabular}

* Composta por: trancamento, cancelamento, reprovação e transferência.

** Dados oriundos da Secretaria de Registro Acadêmico

A formação deficiente, por sua vez, reflete um cenário desfavorável ao aluno que, quando consegue se manter no curso até a sua conclusão, suportando e superando suas dificuldades, acaba tendo uma formação incapaz de fornecer os instrumentos para a superação de sua condição social. Entretanto, também foram apontados, pelos professores, mecanismos para superação dessas dificuldades. São, algumas vezes, ações que envolvem atribuições da gestão, como também ações docentes, isto é, operadas na própria dinâmica da sala de aula, conforme demonstra o Quadro 03.

\section{Quadro 03 - Dificuldades dos alunos e seus mecanismos de enfrentamento segundo os professores entrevistados}

\begin{tabular}{c|c}
\hline Dificuldades & Soluções \\
\hline $\begin{array}{c}\text { Falta de flexibilidade no ambiente } \\
\text { de trabalho para realizar atividades } \\
\text { do curso. }\end{array}$ & $\begin{array}{c}\text { Sensibilização das empresas. Parceria para } \\
\text { flexibilização de horário. Ampliação da oferta } \\
\text { de bolsas de assistência estudantil. }\end{array}$ \\
\hline $\begin{array}{c}\text { Falta de tempo para as atividades } \\
\text { do curso }\end{array}$ & $\begin{array}{c}\text { Flexibilização de horários. } \\
\text { acompanhamento do conteúdo das }\end{array}$ \\
$\begin{array}{c}\text { Mudanças na forma de ingresso. Participação } \\
\text { dos alunos no atendimento pedagógico } \\
\text { oferecido semanalmente pelos professores. }\end{array}$ \\
\hline Desconhecimento prévio do curso & Palestra informativa anterior à inscrição no \\
\hline
\end{tabular}




\begin{tabular}{c|c}
\hline $\begin{array}{c}\text { Dificuldade no entendimento dos } \\
\text { conteúdos/falta de pré-requisito. }\end{array}$ & $\begin{array}{c}\text { curso } \\
\text { técnico) para ingresso nos cursos } \\
\text { subsequentes. Revisão dos conteúdos } \\
\text { propedêuticos. }\end{array}$ \\
\hline $\begin{array}{c}\text { Ausência de estrutura de apoio ao } \\
\text { aluno (física, pedagógica e social) }\end{array}$ & $\begin{array}{c}\text { Ajuste no plano de metas de acordo com as } \\
\text { condições existentes de oferta. }\end{array}$ \\
\hline $\begin{array}{c}\text { Distância e dificuldades de acesso } \\
\text { aos locais do curso }\end{array}$ & $\begin{array}{c}\text { Distribuição de vales-transportes. } \\
\text { Aesmotivação em relação ao curso }\end{array}$ \\
\hline $\begin{array}{c}\text { Ampliação do atendimento da assistência } \\
\text { social e psicológica. }\end{array}$ \\
\hline $\begin{array}{c}\text { Falta de planejamento da } \\
\text { instituição em relação à }\end{array}$ & $\begin{array}{c}\text { Mudanças no horário das aulas. Flexibilização } \\
\text { pelo professor. }\end{array}$ \\
\hline $\begin{array}{c}\text { Necessidade de trabalhar para } \\
\text { ajudar no orçamento domás das diretrizes norteadoras } \\
\text { ajtes da implantação dos cursos. }\end{array}$ & $\begin{array}{c}\text { Aumento na oferta e nos valores das bolsas de } \\
\text { estudo. }\end{array}$ \\
\hline
\end{tabular}

Fonte: Pesquisa de Campo, 2011.

Boa parte das ações mencionadas pelos professores está em curso e faz parte da política do IFB, a saber: (a) realização de palestras informativas para os alunos, antes da inscrição nos cursos; (b) mudanças nos horários das aulas; e (c) oferta de assistência social e psicológica. Outras, porém, foram mencionadas como sugestão para implementação em sala de aula e podem ser efetivadas pelos professores, como flexibilização quanto ao atraso nas aulas e revisão dos conteúdos propedêuticos. Apesar das dificuldades enfrentadas, os alunos apresentam expectativas em relação aos cursos.

Quase a totalidade dos alunos participantes da pesquisa afirmou que os conhecimentos adquiridos no curso são fundamentais para sua trajetória profissional $(93 \%)$. Isso demonstra uma expectativa em relação à formação recebida. Além disso, quando questionados sobre a qualidade do curso que frequentam, $77 \%$ afirmaram que a qualidade é excelente ou ótima. Tal constatação revela a compreensão de que, além de boa qualidade, é também um curso com alto potencial de empregabilidade.

\section{O DISCURSO OFICIAL DA INCLUSÃO E A TENTATIVA DE SUPERAÇÃO DA DUALIDADE ESTRUTURAL}

Implementar políticas públicas que consigam promover a inclusão de pessoas em espaços sociais mais privilegiados, mediante a defesa do direito a uma vida mais digna parece ser o objetivo de todo e qualquer governo de aspiração humanista e democrática. A questão que se coloca é: as ações dos governos que materializam as políticas públicas são capazes de alcançar este resultado? No caso específico da educação, soma-se a esse desafio a crença messiânica e ingênua no poder transformador da sociedade por intermédio da escola. Sem dúvida, as instituições de ensino têm responsabilidade na dinâmica e construção 
social, mas sozinhas não são capazes de fazer desaparecer as injustiças sociais. O discurso oficial da inclusão, por exemplo, reflete a crença de que a educação, por si só, será capaz de transformar a realidade social, por meio, dentre outros, da inserção das pessoas no mercado de trabalho. Nos documentos oficiais, 0 discurso da inclusão é revelado pelas seguintes categorias: inclusão, justiça social, equidade e cidadania. São categorias presentes na maioria dos documentos oficiais analisados, seja implícita ou explicitamente. Ao estabelecer o papel da inclusão, por exemplo, através das "Diretrizes para a Extensão", expressas no Plano de Desenvolvimento Institucional (PDI) para o período de 2009 a 2013, o Instituto Federal de Brasília propõe "articular políticas públicas que oportunizem o acesso à educação profissional, estabelecendo mecanismos de inclusão". Nessa diretriz, o termo inclusão ajuíza a necessidade de criação de instrumentos que a torne possível, efetivamente, embora tais mecanismos não estejam definidos expressamente no texto do documento.

Outro aspecto importante é a concepção da relação entre trabalho e educação subjacente aos documentos oficiais. No artigo 29 do Estatuto do IFB, por exemplo, a perspectiva que se abre para essa relação é de que o ensino deve pautar-se numa relação integradora e não excludente. A concepção que se tem é de tomar a "educação como processo de formação na vida e para a vida, a partir de uma concepção de sociedade, trabalho, cultura, educação e tecnologia". A integração que se propõe no texto do documento está longe de ser alcançada e se difere totalmente da realidade verificada na pesquisa através das dificuldades levantadas pelos alunos e relatadas pelos professores. O trabalho, que oficialmente aparece como um princípio educativo, é o principal fator de dificuldade para permanência nos cursos e para a permanência com sucesso e aproveitamento.

Também a própria noção de trabalho subjacente aos documentos oficiais de âmbito nacional (Lei 11.741/2008) que é reproduzida através das diretrizes pedagógico-administrativas internas revela uma contradição percebida na definição dos cursos de Formação Inicial e Continuada - FICs. São cursos voltados para a qualificação profissional e buscam atender demandas específicas do mercado de trabalho, sem a preocupação com a formação ampla do trabalhador no sentido de torná-lo capaz de compreender de maneira holística o processo produtivo e seus fundamentos científicos inerentes. Como objetivo institucional, o IFB considera: "ministrar cursos de formação inicial e continuada de trabalhadores, objetivando a capacitação, o aperfeiçoamento, a especialização e a atualização de profissionais, em todos os níveis de escolaridade" (PDI/IFB, $2009 / 2013$, p. 13). Trata-se de uma política incompatível com a constatação de que as transformações sociais exigem um profissional com sólida formação, capaz de atuar de forma competente neste mercado de trabalho cada vez mais exigente. Para além da discussão sobre o conceito de formação inicial versus formação continuada, inerente a nova forma de oferta de educação profissional, cuja polêmica não será abordada nesta discussão, a qualificação aligeirada para o mercado de trabalho confronta a noção de trabalho como princípio educativo.

Ora, o conceito de trabalho como princípio educativo é radicalmente incompatível com a formação de "recursos humanos", noção proveniente da teoria do capital humano. $\mathrm{Na}$ verdade, o trabalho como princípio educativo é um dos 
princípios fundantes do EM integrado e da politecnia. Tal princípio permite a compreensão do significado econômico, social, histórico, político e cultural das ciências e das artes, o que implica considerar o trabalho em seus sentidos ontológico e histórico. Em sua dimensão ontológica, considerar o trabalho como princípio educativo é compreendê-lo como relação fundamental entre o homem e a natureza e, desse modo, central na produção da existência humana (MOURA, 2010, p. 886).

Sem uma formação verdadeiramente capaz de tornar o trabalhador preparado para se integrar nos processos produtivos, com conhecimentos que ultrapassam o adestramento técnico e a repetição de tarefas cuja execução prescinde de compreensão, análise e crítica, o projeto de inserir trabalhadores no mercado, tendo como pano de fundo o discurso da inclusão social, torna-se inócuo.

\section{CONSIDERAÇÕES FINAIS}

O objetivo desta pesquisa foi analisar as causas e as consequências da evasão no Instituto Federal de Brasília, à luz do fenômeno sociológico da dualidade estrutural em comparação com o discurso oficial da inclusão presente nos documentos institucionais. Essas perspectivas estão diretamente vinculadas às condições para permanência nos cursos, que são inviabilizadas pelas dificuldades enfrentadas pelos alunos. Essas dificuldades, portanto, se impõem como condições desafiadoras para que os estudantes consigam se manter nos cursos com níveis de aproveitamento razoáveis. Todavia, ainda que as expectativas em relação ao curso sejam otimistas, a condição social dos alunos, o fato de trabalharem, combinados com uma faixa etária elevada contribuem para o incremento dessas dificuldades.

Por outro lado, a evasão tem apresentado altos índices no final do primeiro semestre dos cursos, podendo chegar a mais de $50 \%$ ao final do segundo módulo, conforme já demonstrado.

Nesse sentido, a pesquisa mostrou que a dualidade estrutural continua presente na realidade educacional dos alunos dos cursos técnicos subsequentes do Instituto Federal de Brasília e permanece como categoria explicativa importante para se pensar a realidade dos cursos técnicos no Brasil.

No discurso oficial, o trabalho aparece como um princípio educativo, mas na prática essa, que é uma condição dos alunos, não contribui para cumprir a sua função de criar mecanismos para uma subsistência emancipatória, ora como instância de vida a serviço da formação; ora como fim último dessa formação. Há fatores que contribuem para que isso ocorra, como a falta de tempo, as responsabilidades com a família, o cansaço e as faltas recorrentes. Essas dificuldades comprometem o bom aproveitamento do curso, dificultando sua 
emancipação social por meio da educação. As altas taxas de evasão demonstram que é preciso rever a operacionalização das políticas educativas, para que ações bem intencionadas, como o ingresso por sorteio sem um posterior nivelamento, por exemplo, não se configure em oferta de escadas a sem-pernas.

\section{REFERÊNCIAS}

ANDRÉ, M. E. D. A. Etnografia da prática escolar. São Paulo: Papirus, 1995.

ARAúJO, C. H. Avaliação da Educação Básica: em busca da qualidade e equidade no Brasil. Brasília: Instituto Nacional de Estudos e Pesquisas Educacionais Anísio Teixeira, 2005.

BARDIN, L. Análise de Conteúdo. Portugal: Edições 70, 1977.

BORGAN, R. C. BIKLEN, S. K. Investigação Qualitativa em Educação. PortoPortugal: Porto Editora, 2010.

BRASIL, Constituição(1934) Constituição dos Estados Unidos do Brasil - 16 de julho de 1934. Disponível em: www.planalto.gov.br. Acesso em 02 de Abr de 2012.

BRASIL, Lei 5692 (1971). Organiza os ensinos de primeiro e segundo graus. Disponível em: www.planalto.gov.br. Acesso em 02 de Abr de 2012.

BRASIL, LDB. Lei 9394 (1996). Lei de Diretrizes e Bases da Educação Nacional. Disponível em: www.planalto.gov.br. Acesso em: 02 de Abr de 2012.

BRASIL, Lei 11.741 (2008). Integra as ações da educação profissional com a educação de jovens e adultos. Disponível em: www.planalto.gov.br. Acesso em 02 abr. 2012.

BRASIL, Lei 4.024 (1961). Lei de Diretrizes e Bases da Educação Nacional. Disponível em: www.planalto.gov.br. Acesso em 02 de Abr de 2012.

BRASIL. Lei no 11.892. (2008). Institui a Rede Federal de Educação Profissional, Científica e Tecnológica, cria os Institutos Federais de Educação, Ciência e Tecnologia. Disponível em www.planalto.gov.br. Acesso em 02 de abr. de 2012.

CURY, C. R. J. A educação básica como direito. Cadernos de Pesquisa, v. 38, n. 134 , p. 293-303, maio/ago. 2008, p. 293 - 203

MOURA, D. H. A relação entre a educação profissional e a educação básica na conae 2010: possibilidades e limites para a construção do novo plano nacional de educação. Educ. Soc., Campinas, v. 31, n. 112, p. 875-894, jul.-set. 2010

FAZENDA, I. A pesquisa em educação e as transformações do conhecimento. 2. ed. São Paulo: Papirus Editora, 1997. 
ROSA, M. V. F P. C. A entrevista na pesquisa qualitativa: mecanismos para validação dos resultados. Belo Horizonte: Autêntica, 2008.

SAVIANI, D. Trabalho e educação: fundamentos ontológicos e históricos. Revista Brasileira de Educação v. 12 n. 34 jan./abr. 2007, p. 152 - 180.

SAVIANNI, D. Escola e Democracia: teorias da educação, curvatura da vara, onze teses sobre a educação política. 39. Ed.Campinas, SP: Autores Associados, 2007.

SILVA, C. N. N. Função e disfunção do ensino médio profissionalizante no Brasil. Ideias universitárias, no 1, Formosa. 2004, p. 25 - 31.

KUENZER, A. Z. Da dualidade assumida à dualidade negada: o discurso da flexibilização justifica a inclusão excludente. Educ. Soc., Campinas, vol. 28, n. 100 - Especial, p. 1153-1178, out. 2007.

Recebido em: 17/01/2013

Aceito em: 16/04/2013 